\title{
Effects of Moderate Altitude on Exhaled Nitric Oxide, Erythrocytes Lipid Peroxidation and Superoxide Dismutase Levels
}

\author{
Nevin Atalay GÜZEL, Hale SAYAN, and Deniz ERBAS \\ Department of Physiology, Faculty of Medicine, Gazi University, Ankara, Turkey
}

\begin{abstract}
The purpose of this study was to investigate the effects of staying at a moderate altitude $(2,300 \mathrm{~m}, 7 \mathrm{~d})$ on the levels of plasma nitrite, exhaled nitric oxide (NO), malondialdehyde (MDA) and superoxide dismutase (SOD). Measurements were obtained from 9 female (mean age 18.3 \pm 2 ) and 9 male (mean age 19.3 \pm 3.7 ) cross-country volunteer skiers: before, during (1st day, 7th day) and after staying at a moderate altitude. Exhaled nitric oxide levels were measured only before and after staying at the alti-
\end{abstract}

tude. Nitrite levels increased throughout the stay at the altitude, while MDA levels decreased. In parallel with the nitrite levels, SOD activities were also found to have increased. Exhaled NO values were decreased after the stay at the moderate altitude. These results show that altitude hypoxia causes decreased in NO levels in the lung but increased systemic NO levels in the blood due to inhibition of erythrocyte lipid peroxidation. [Japanese Journal of Physiology, 50, 187-190, 2000]

Key words: $\quad$ nitric oxide, nitrite, superoxide dismutase, lipid peroxidation, altitude.

$\mathrm{P}_{\text {hy }}$ mon as one of the luxuries of modern life. Physical activities begin to be affected at about the elevation of $1,300 \mathrm{~m}$ due to reductions in ventilation. Endurance (aerobic) exercises are affected more by altitude than sprinting or anaerobic exercise. Training time for acclimatization needs to be longer as the altitude becomes higher [1].

Several researchers have investigated the reactive oxygen species (ROS) production activity of circulating neutrophils after exercise and have reported conflicting findings including increases, decreases or no change in the response [2]. The variability in the findings could be attributable to the difference in the intensity and duration of exercise or the sampling point for the assesment. Hack et al. reported increased ROS after $1 \mathrm{~d}$ of exercise [3]. In many studies, ROSs' are found to be decreased after exercise [4]. Physical exercise at high altitude decreases the generation of free radical species and activity of superoxide dismutase (SOD) [5]. At high altitude, the decreased filterability of erythrocytes may be due to increased lipid peroxi- dation [6]. Radak et al. (1997) have shown that 4 weeks of exercise at an altitude of $4,000 \mathrm{~m}$ increased the activity of mitochondrial SOD in skeletal muscle [5]. Exhaled nitric oxide increases through exercise, but there is no information for high altitude. In this study, we aimed to determine the effect of high altitude on the oxidant-antioxidant mechanisms and $\mathrm{NO}_{x}$ levels in trained subjects.

\section{MATERIALS AND METHODS}

This study was performed using nine healthy male (mean age 19.3 \pm 3.7 ) and nine healthy female (mean age $18.3 \pm 2$ ) cross-country skiers with at least 1 year of experience. They individually prepared themselves by endurance training daily for $1.5 \mathrm{~h}$ by skiing at low ( $856 \mathrm{~m}$ above sea level in Ankara) and moderate $\left(2,300 \mathrm{~m}\right.$ above sea level in Erciyes, $\mathrm{PO}_{2}$ was $83 \mathrm{~mm} \mathrm{Hg}$ ) altitudes. The period of stay at the moderate altitude was $7 \mathrm{~d}$. All of the blood measurements were performed before ( $12 \mathrm{~h}$ before moving to the moderate altitude), during (1st day and 7 th day) and

Received on June 12, 1999; accepted on December 29, 1999

Correspondence should be addressed to: Nevin Atalay Guzel, Department of Physiology, Faculty of Medicine, Gazi University, 06500, Beşevler, Ankara, Turkey. Fax: +90-312-4688171, E-mail: nevinag@yahoo.com 
Table 1. The values determined from trained skiing subjects.

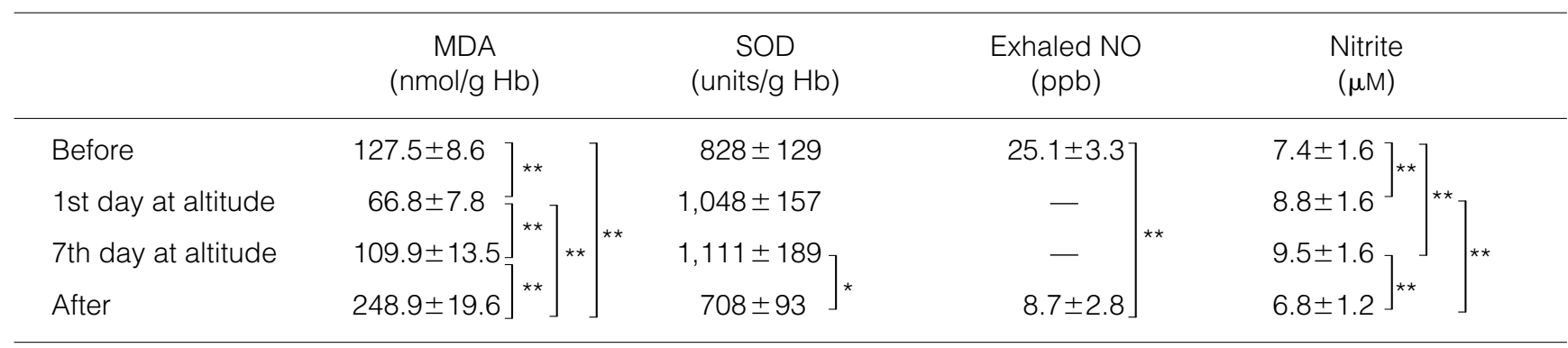

$n=18$. Values are means \pm SD. ${ }^{*} p<0.05,{ }^{* *} p<0.01$.

after ( $12 \mathrm{~h}$ after leaving the moderate altitude) the stay at the moderate altitude. Blood was sampled by venipuncture. Exhaled NO levels were measured using a Sievers NOA 280 model chemiluminescence analyzer.

Nitrite measurement. The amount of total nitrite in the test samples was determined by a modification of the procedure described by Braman and Hendrix [7], using the purge system of a Sievers Instruments Model 280A Nitric Oxide Analyzer. Glacial acetic acid $(4 \mathrm{ml})$ and $1 \mathrm{ml}$ of $\mathrm{NaI}(69 \mathrm{mg}$ in $1 \mathrm{ml}$ deionized water) were added to the purge vessel and purged with nitrogen gas for 10 min prior to use. Cell pressure was $\sim 6$ torr.

Samples were injected into the purge vessel to react with the glacial acetic acid and NaI, which convert nitrite into NO. The NO produced was isolated from the reaction chamber and detected by ozone-induced chemiluminescence in the chemiluminescence detector. Parts per billion (ppb) values detected and sample NO levels were calculated from the peak values.

A standard curve was drawn using various concentrations of $\mathrm{NaNO}_{2}^{-}$(10 to $\left.100 \mu \mathrm{M}\right)$. Sample nitrite levels were calculated using the standard curve. Results were expressed as the means \pm SD.

The amount of thiobarbituric acid (TBA) reactive substance (MDA) as an index of lipid peroxidation and superoxide dismutase (SOD) levels was assayed by spectrophotometry as follows.

Lipid peroxidation. Isoosmotic phosphatesaline buffers were used to wash red-cells as well as suspending media. The red-cell suspension was preincubated with hydrogen peroxide (at $37^{\circ} \mathrm{C}$ for $2 \mathrm{~h}$ ). Two milliliters TCA-arsenit and $1 \mathrm{ml}$ TBA solution were added to $4 \mathrm{ml}$ of the cell suspension. The mixture was placed in a boiling water bath for $15 \mathrm{~min}$. The absorbance at $532 \mathrm{~nm}$ was read [8].

SOD assay. The red cells were washed with saline and hemolysed by adding 1.5 volumes of water. A chloroform-ethanol extract was prepared by adding $0.5 \mathrm{ml}$ of hemolysate to $3.5 \mathrm{ml}$ of ice-cold distilled water, followed by $1 \mathrm{ml}$ of ethanol and $0.6 \mathrm{ml}$ chloroform, and then well shaken. Tubes were centrifugated. A stock solution was then prepared with phosphate buffer, $0.1 \mathrm{M}$ EDTA containing $1.5 \mathrm{mg}$ of $\mathrm{NaCN}$ per $100 \mathrm{ml}, 0.12 \mathrm{mM}$ riboflavin and $1.5 \mathrm{nM}$ NBT. For each sample to be assayed, 3 tubes were set up containing $80,80,500 \mu \mathrm{l}$ red-cell extract, plus $0.2 \mathrm{ml}$ EDTA/ $\mathrm{NaCN}, 0.1 \mathrm{ml} \mathrm{NBT}, 0.5 \mathrm{ml}$ riboflavin and phosphate buffer to give a total volume of $3 \mathrm{ml}$. The tubes were placed in a light box, and then optical densities were measured at $560 \mathrm{~nm}$ [9].

Statistical analysis. Statistical analysis was performed by analysis of variance (ANOVA), and differences between the groups were tested by the Wilcoxon test.

\section{RESULTS}

All measured values are shown in Table 1. The MDA levels decreased significantly throughout the stay at high altitude, whereas SOD and nitrite levels increased. The MDA content in erythrocytes significantly increased 1 day after staying at the high-altitude $(248.9 \pm 19.6 \mathrm{nmol} / \mathrm{g} \mathrm{Hb}, p<0.01)$, but SOD content decreased $(708.3 \pm 93.3$ units/g $\mathrm{Hb}, p<0.05)$. MDA content on the 1st and 7th days of being at high altitude decreased significantly $(66.82 \pm 7.79$ and $109.9 \pm 13.5 \mathrm{nmol} / \mathrm{g} \mathrm{Hb}$, respectively) compared to before $(127.47 \pm 8.56 \mathrm{nmol} / \mathrm{g} \mathrm{Hb})$ and after staying at high altitude $(248.9 \pm 19.6 \mathrm{nmol} / \mathrm{g} \mathrm{Hb}, p<0,01)$. However, the SOD content was found to be increased on the 1 st and 7 th days at high altitude $(1,048 \pm 157$ and $1,111 \pm 189$ units/g Hb, respectively). But this increase was not significant.

Exhaled NO levels $(25.1 \pm 3.3)$ decreased significantly $(p<0.01)$ after staying at high altitude $(8.7 \pm 2.8)$ as compared to former levels.

Nitrite values increased $(p<0.01)$ throughout the period of stay at high altitude. 


\section{DISCUSSION}

Exercise increases the cellular metabolism and thus enhances the leakage of oxygen-derived free radicals into the plasma [10]. MDA (as a reference for lipid peroxidation) decreased throughout the period of stay at high altitude. Gürcan and co-workers found decreased levels of erythrocyte MDA immediately after submaximal exercise [11]. Hack et al. also found increased MDA levels $1 \mathrm{~d}$ after exercise [3]. Our findings confirmed the results of both studies.

SOD activity increased throughout the stay at moderate altitude showing a negative correlation with regard to MDA levels. Decreased ROS levels should be the cause of the increase in SOD activity.

The number of leucocytes increases in response to stressfull stimuli including exercise. Their source is in the marginal layer along vessel walls. Acute bouts of exercise cause a significant increase in leucocyte number [12]. These findings are also in agreement with our findings.

Low oxygen tension has been shown to inhibit the activity of isolated NOS enzymes [13]. Fike and coworkers have shown that exhaled $\mathrm{NO}$ outputs and plasma $\mathrm{NO}_{x}$ were lower in chronically hypoxic than in control piglets. Also, perfusate accumulation of $\mathrm{NO}_{x}$ was lower in chronic hypoxia than in controls [14]. Carlin and co-workers have also shown a dose-dependent decrease in exhaled NO in hypoxic rabbits [15]. Hyperoxia increases the level of exhaled NO, which indicates increased NO production. The mechanism behind this phenomenon remains to be elucidated [16]. With regard to these findings, our decreased exhaled NO levels confirmed the decreased NO production in the lungs of the skiing subjects. The respiratory system is the most likely source of the reduced exhaled NO output. This is the first information about the exhaled NO-high-altitude relationship.

NO is also continuously released in the systemic circulation and attenuates the arterial pressure [17]. Shear stress is a probable stimulus for NO release. Hypoxic vasoconstriction may also provoke NO release in proportion to its severity [17]. The end metabolic product of NO is nitrite and nitrate. We determined the increased plasma nitrite levels throughout the period of stay at moderate altitude and show the increased NO production in the body.

Lubec and co-workers have shown that L-arginine treatment (substrate for NO synthesis) was able to reduce the lipid peroxidation product MDA [18]. Our results also confirmed the findings that decreased MDA levels were observed when nitrite (end product of NO) levels were high.
In conclusion, chronic hypoxia at moderate altitude in skiing subjects causes increased $\mathrm{NO}_{x}$ levels and SOD activity as well as lowers the ROS and exhaled $\mathrm{NO}$ levels. Combined use of inhaled $\mathrm{NO}$ and $\mathrm{O}_{2}$ may be useful for pulmonary hemodynamics and gas exchange in skiing subjects at high altitude [19].

This work was supported by the Turkish Prime Ministry State Planning Organization and Gazi University Research Center.

\section{REFERENCES}

1. Graetzer D: High altitude and its effects on exercise performance. http://www.livelinks.com/sumeria/oxy/ altitude.html

2. Suzuki $\mathrm{K}$ and Sato $\mathrm{H}$ : Capacity of circulating neutrophils to produce reactive oxygen species after exhaustive exercise. J Appl Physiol 81: 1213-1222,1996

3. Hack V, G Strobel J, Raul P, and Weicker R: The effect of maximal exercise on the activity of neutrophil granulocytes in highly trained athletes in a moderate training period. Eur J Appl Physiol Occup Physiol 65: 520524,1992

4. Hack V, G Strobel J, J Weiss M, and Weicker R: PMN cell counts and phagocytic activity of highly trained athletes depend on training period. J Appl Physiol 77: 1731-1735, 1994

5. Radak Z, Asano K, Lee KC, Ohno H, and Nakamura A: High altitude training increases reactive carbonylderivatives but not lipid peroxidation in skeletal muscle of rats. Free Radical Biol Med 22: 1100-1114, 1997

6. Simon and Schnaos IM: Nutrition at high-altitude. J Nutr 122: 778-781, 1992

7. Braman RS and Hendrix SA: Nanogram nitrite and nitrate determination in environmental and biological materials by vanadium (III) reduction with chemiluminescence detection. Anal Chem 61: 2715-2718, 1989

8. Stocks $J$ and Dormandy TL: The autooxidation of human red cell lipids induced by hydrogen peroxide. Br J Hematol 20: 95-111, 1971

9. Winterbourn CC, Hawkins RE, Brian M, and Carrel WR: The estimation of red cell superoxide dismutase activity. J Lab Clin Med 85: 337-341, 1975

10. Duthie GG, Robertson JD, Maughan JR, and Morrice CP: Blood antioxidant status and erythrocyte lipid peroxidation following distance running. Arch Biochem Biophys 282: 78-83, 1990

11. Gürcan N, Erbas D, and Ergen E: Changes in blood hemorheological parameters after submaximal exercise in trained and untrained subjects. Physiol Res 47: 23-27, 1998

12. Hansen JB, Wilsgard L, and Osterud B: Biphasic changes in leukocytes induced by strenuous exercise. Eur J Appl Physiol 62: 157-161, 1991

13. Le Cras TD, Xue C, and Rengesamy A: Chronic hypoxia upregulates endothelial and inducible NO synthase gene and protein expression in rat lung. Am J Physiol 270 (Lung Cell Mol Physiol 14): 164-170, 1996

14. Fike CD, Kaplowitz MR, and Thomas CJ: Chronic hypoxia decreases nitric oxide production and endothe- 
lial nitric oxide synthase in newborn pig lungs. Am J Physiol 274 (Lung Cell Mol Physiol 4): 517-526, 1998

15. Carlin RE, Ferrario R, Boyd JT, Camporesi EM, and McGraw DJ: Determinants of nitric oxide in exhaled gas in the isolated rabbit lung. Am J Respir Crit Care Med 155: 922-927, 1997

16. Schmetterer L, Strenn K, Kastner J, Eichler HG, and Wolzt M: Exhaled NO during graded changes in inhaled oxygen in man. Thorax 52: 936-938, 1997

17. Barer G, Emery C, and Stewart A: Endothelial control of the pulmonary circulation in normal and chronically hypoxic rats. J Physiol (Lond) 463: 1-16, 1993

18. Lubec B, Hayn M, and Kitzmüller $E$ : L-Arginine reduce lipid peroxidation in patients with diabetes mellitus. Free Radical Biol Med 22: 335-357, 1997

19. Anand IS, Prasad BA, Chung SS, Rao KR, Cornfield DN, Milla CE, Singh N, Singh S, and Selvamurthy W: Effects of inhaled nitric oxide and oxygen in high altitude pulmonary edema. Circulation 98: 2441-2445, 1998 